ISSN 0103-9954

\title{
PRODUÇÃO DE SERAPILHEIRA EM FLORESTA ESTACIONAL SEMIDECIDUAL E EM PLANTIOS DE Pterogyne nitens Tul. e Eucalyptus urophylla S. T. Blake NO SUDOESTE DA BAHIA
}

\author{
LITTER PRODUCTION IN SEASONAL SEMIDECIDUOUS FOREST AND Pterogyne nitens Tul. \\ AND Eucalyptus urophylla S. T. Blake PLANTATIONS IN SOUTHWESTERN BAHIA STATE, \\ BRAZIL
}

\author{
Alcides Pereira Santos Neto ${ }^{1}$ Patrícia Anjos Bittencourt Barreto ${ }^{2}$ \\ Emanuela Forestieri da Gama-Rodrigues ${ }^{3}$ Adalberto Brito de Novaes ${ }^{4}$ Alessandro de Paula ${ }^{5}$
}

\begin{abstract}
RESUMO
A serapilheira constitui um dos principais componentes responsáveis pela manutenção da capacidade produtiva de sítios florestais e, sendo assim, o conhecimento da sua produção e composição pode fornecer subsídios para adequação de técnicas de manejo. O objetivo deste trabalho foi avaliar mensalmente a serapilheira produzida em uma Floresta Estacional Semidecidual (mata de cipó) e dois plantios florestais puros (de Pterogyne nitens e de Eucalyptus urophylla), localizados no município de Vitória da Conquista - BA, assim como analisar a influência de fatores climáticos nessa produção. As amostras da serapilheira foram coletadas durante dez meses, por meio de coletores quadrados com $0,25 \mathrm{~m}^{2}$. Os materiais coletados foram triados (frações: folhas, galhos, casca e estruturas reprodutivas) e secos em estufa a $60^{\circ} \mathrm{C}$. As produções mensais médias de serapilheira foram de 544,6, 522,6 e 179,5 $\mathrm{kg}^{\text {ha }}{ }^{-1}$ nas áreas de mata de cipó, Eucalyptus urophylla e Pinus nitens, respectivamente. As folhas representaram maior proporção da serapilheira produzida nas três coberturas $(65 \%$ do total). A produção mensal média de folhas foi superior na mata nativa, seguida do Eucalyptus urophylla e Pinus nitens. O aporte de galhos foi significativamente menor no povoamento de Pinus nitens e não variou entre mata de cipó e Eucalyptus urophylla. A produção de materiais reprodutivos variou na ordem: Eucalyptus urophylla $>$ mata de cipó $>$ Pinus nitens. A fração casca não variou entre mata de cipó e Pinus nitens, sendo superior no Eucalyptus urophylla. Em todas as coberturas estudadas verificou-se correlação significativa negativa entre produção total e temperatura média do ar. Apenas no plantio de Pinus nitens foram verificadas associações significativas do aporte de serapilheira com as variáveis precipitação e velocidade do vento. O Eucalyptus urophylla e a mata de cipó apresentam similaridade quanto à produção média de serapilheira, sendo cerca de $67 \%$ superior a produção de Pinus nitens. A variação temporal do aporte de serapilheira de Pinus nitens mostra-se bem mais sensível à influência de variáveis climáticas que a mata de cipó e o Eucalyptus urophylla. A contribuição das frações da serapilheira obedeceu a uma mesma ordem em todas as coberturas estudadas: folhas $>$ galhos $>$ estruturas reprodutivas $>$ cascas.
\end{abstract}

Palavras-chave: folhedo; deposição; madeira nova; eucalipto.

1 Engenheiro Florestal, Mestrando em Ciências Florestais, Universidade Federal do Espírito Santo, Av. Governador Lindemberg, Centro, CEP 29550-000, Jerônimo Monteiro (ES), Brasil. alcidespsneto@yahoo.com.br

2 Engenheira Florestal, Dra., Professora Adjunta do Departamento de Engenharia Agrícola e Solos, Universidade Estadual do Sudoeste da Bahia, Estrada do Bem Querer, km 04, Caixa Postal 95, CEP 45031-300, Vitória da Conquista (BA), Brasil. patriciabarreto@uesb.edu.br

3 Engenheira Agrônoma, Dra., Professora Associada do Laboratório de Solos, Universidade Estadual do Norte Fluminense, Av. Alberto Lamego, s/n, CEP 28013-602, Campos dos Goytacazes (RJ), Brasil. emanuela@uenf.br

4 Engenheiro Agrônomo, Dr., Professor Pleno do Departamento de Fitotecnia e Zootecnia, Universidade Estadual do Sudoeste da Bahia, Estrada do Bem Querer, km 04, CEP 45031-300, Vitória da Conquista (BA), Brasil. adalberto.brito@globo.com

5 Engenheiro Florestal, Dr., Professor Adjunto do Departamento de Engenharia Agrícola e Solos, Universidade Estadual do Sudoeste da Bahia, Estrada do Bem Querer, km 04, CEP 45031-300, Vitória da Conquista (BA), Brasil.apaula@uesb.edu.br

Recebido para publicação em 28/12/2011 e aceito em 10/10/2013

Ci. Fl., v. 25, n. 3, jul.-set., 2015 


\begin{abstract}
Leaf litter is a major component responsible for maintaining the productive capacity of forests; thus, knowledge on their production and composition can provide information to adjust management techniques. The objective of this study was to evaluate the monthly litter fall in a Seasonal Semideciduous Forest and two pure forest plantations (Pterogyne nitens and e de Eucalyptus urophylla), located in city of Vitoria da Conquista, Bahia state, as well as to analyze the influence of climatic factors in this production. Leaf litter samples were collected during ten months, using $0.25 \mathrm{~m}^{2}$ square collectors. The materials collected were screened (fractions: leaves, branches, bark and reproductive structures) and dried in a dry kiln at $60^{\circ} \mathrm{C}$. The monthly average litter productions were $544.6,522.6$ and $179.5 \mathrm{~kg} \mathrm{ha}^{-1}$ in areas of Seasonal Semideciduous Forest, Eucalyptus urophylla and Pinus nitens, respectively. The leaves represented an increasing proportion of litter in three coverages ( $65 \%$ of the total). The average monthly production of leaves was higher in native forest, followed by Eucalyptus urophylla and Pinus nitens. The contribution of branches was significantly lower in the Pinus nitens and did not vary between Seasonal Semideciduous Forest and Eucalyptus urophylla. The production of reproductive materials varied in the order: Eucalyptus urophylla $>$ Seasonal Semideciduous Forest $>$ Pinus nitens. The bark fraction did not vary between Seasonal Semideciduous Forest and Pinus nitens, being higher in Eucalyptus urophylla. There was a significant negative correlation between total production and average air temperature in all studied coverage. Only on Pinus nitens were found significant associations with the litter production variables precipitation and wind speed. Eucalyptus urophylla forest and Seasonal Semideciduous Forest have similar aspects regarding leaf litter production, $67 \%$ higher than the production of Pinus nitens. The temporal variation of litter production of Pinus nitens shows up much more sensitive to the influence of climatic variables that Seasonal Semideciduous Forest and Eucalyptus urophylla. The contribution of litter fractions followed the same order in all coverage studied: leaves $>$ branches $>$ reproductive structures $>$ bark.
\end{abstract}

Keywords: litter fall; deposition; madeira nova (new wood); eucalypts.

\section{INTRODUÇÃO}

As florestas oferecem produtos e serviços diversificados, contribuindo para o desenvolvimento ambiental, econômico e social em todo o mundo. $\mathrm{O}$ Brasil destaca-se quanto à proporção da área florestal em todo o território do País, onde as florestas naturais e plantadas representam $60,7 \%$ do território nacional (SFB, 2010). Nesse cenário, o Estado da Bahia possui a quarta maior área de florestas plantadas, totalizando 659.480 ha (ABRAF, 2010).

$\mathrm{Na}$ Região Sudoeste da Bahia, particularmente no Planalto da Conquista, o extenso histórico de degradação dos recursos naturais tem restringido os remanescentes florestais a pequenos fragmentos (SOARES FILHO, 2000). Como consequência, diante da elevada demanda energética vegetal, verifica-se uma ascensão das áreas de plantios florestais. Nessa condição, informações acerca da dinâmica destes povoamentos, além da indicação de espécies adaptadas às condições edafoclimáticas da região, tornam-se fundamentais para a sustentabilidade destes ecossistemas.

A manutenção da capacidade produtiva de sítios florestais está estreitamente relacionada a vários componentes ecológicos, dentro os quais está a serapilheira (SCHUMACHER et al., 2004), que compreende todos os materiais vegetais depositados na superfície do solo, como folhas, galhos, cascas, troncos, flores, inflorescências, frutos e sementes, além de fragmentos vegetais (FACELLI e PICKETT, 1991; ARATO et al., 2003).

A serapilheira constitui a principal via de transferência de matéria orgânica e elementos minerais da vegetação para o solo (VITOUSEK e SANFORD, 1986), sendo a composição da cobertura vegetal determinante para as suas taxas de deposição e decomposição, o que interfere diretamente na ciclagem de nutrientes (PINTO et al., 2008).

Diversos estudos sobre aporte de serapilheira e nutrientes têm sido realizados em plantios do gênero Eucalyptus e de outras espécies exóticas, localizados nas mais variadas condições do Brasil (SANKARAN, 1993; MARTINS e RODRIGUES, 1999; PAGANO e DURIGAN, 2001; GAMA-RODRIGUES e BARROS, 2002), entretanto, poucos são aqueles desenvolvidos em 
plantios equiâneos de espécies florestais nativas (GAMA-RODRIGUES E BARROS, 2002; SCHUMACHER et al., 2004; FERREIRA et al., 2007). A utilização de essências nativas em plantios florestais pode apresentar vantagens quanto à adaptação às características ambientais da região e o favorecimento à recuperação de áreas degradadas. Pesquisas recentes evidenciam as potencialidades da madeira nova (Pterogyne nitens Tul.), espécie nativa do Brasil, tanto para a restauração de ecossistemas degradados, quanto para fins comerciais (PAULA e ALVES, 1997). A sua madeira é utilizada como lenha, apresentando boa qualidade devido ao seu poder calorífico (CARVALHO, 1994), e na construção de móveis (LORENZI, 2002). A espécie apresenta rusticidade e rapidez de crescimento, podendo ser utilizada em plantios puros ou mistos. Além disso, por pertencer à família das leguminosas, apresenta potencial para a fixação de nitrogênio.

Diante do exposto, o presente estudo teve como objetivo avaliar mensalmente a serapilheira produzida em um fragmento de uma Floresta Estacional Semidecidual Montana e dois plantios florestais puros (um de Pinus nitens e outro de Eucalyptus urophylla), no Sudoeste da Bahia, assim como analisar a interferência de variáveis climáticas nessa produção.

\section{MATERIAL E MÉTODOS}

\section{Caracterização das áreas de estudo}

$\mathrm{O}$ estudo foi desenvolvido em três áreas, sendo uma de Floresta Estacional Semidecidual Montana (denominada regionalmente de mata de cipó) e duas de plantios florestais homogêneos, de madeira nova (Pterogyne nitens Tul.) e de eucalipto (Eucalyptus urophylla S. T. Blake), com cinco e seis anos de idade, respectivamente, localizados na região Sudoeste do Estado da Bahia, no município de Vitória da Conquista. As áreas de mata de cipó e eucalipto estão situadas nas proximidades da BR 116 (1456’39,46”'S e 4053'49,47'W), distando-se cerca de $12 \mathrm{~km}$ em linha reta da área de madeira nova, situada no Campo Agropecuário da Universidade Estadual do Sudoeste da Bahia (14 $53^{\circ} 1,06^{\prime}$ 'S e $\left.40^{\circ} 47^{\prime} 55,18^{\prime \prime} \mathrm{W}\right)$.

O fragmento de mata de cipó apresenta área íntegra considerável e estágio médio de regeneração, segundo critérios estabelecidos por
Brasil (1994). A vegetação apresenta adaptações para aridez, com folhagem esclerófila de pequeno tamanho e gemas protegidas por pelos, todavia, a maioria das espécies não apresenta acúleos. Trata-se de uma floresta relativamente baixa (árvores com altura entre 10 e $15 \mathrm{~m}$ ), composta de mesofanerófitos parcialmente caducifólios, envolvidos por lianas, com predominância de ecótipos da família Leguminosae, destacando-se o gênero Parapiptadenia (VELOSO et al., 1991).

Os povoamentos de madeira nova e de eucalipto foram estabelecidos em espaçamento $3 \mathrm{~m} \times 3 \mathrm{~m}$, com adubação localizada na cova, composta de 100 gramas de Superfosfato Simples. O preparo do solo consistiu de gradagem e abertura de covas. O povoamento de madeira nova, em decorrência de a espécie possuir crescimento cespitoso, apresentava árvores com um a três fustes, diâmetro a altura de 1,3 m (DAP) variando de 2,9 a $13,5 \mathrm{~cm}$, altura entre 6,1 a $10,5 \mathrm{~m}$ e incremento médio anual (IMA) de $10,1 \mathrm{~m}^{3} \mathrm{ha}^{-1} \mathrm{ano}^{-1}$. O povoamento de eucalipto apresentava-se mais homogêneo, com DAP médio de $16,0 \mathrm{~cm}$, altura média de $16,7 \mathrm{~m}$ e IMA de $29,9 \mathrm{~m}^{3} \mathrm{ha}^{-1}$ ano $^{-1}$.

Aregiãode estudotemrelevoplanoalevemente ondulado, altitude média de $840 \mathrm{~m}$ e clima tropical de altitude (Cwb), segundo classificação de Köppen. Os valores médios de temperatura e precipitação são de $25^{\circ} \mathrm{C}$ e de $850 \mathrm{~mm}$, respectivamente. Os solos das áreas estudadas possuem textura argiloarenosa e pertencem a uma mesma classe: Latossolo Amarelo Distrófico (EMBRAPA, 2006). A Tabela 1 apresenta a caracterização química e granulométrica desses solos na profundidade $0-5 \mathrm{~cm}$.

\section{Amostragens de serapilheira e solo}

As amostras de serapilheira foram coletadas no período de julho de 2010 a abril de 2011, totalizando dez meses de estudo, conforme adotado por Alves et al. (2006), Maman et al. (2007), Vidal et al. (2007) e Machado et al. (2012).

Em cada área, estabeleceram-se quatro parcelas com dimensões de $21 \times 21 \mathrm{~m}$ para as coletas de serapilheira e solo. Em cada parcela, a serapilheira produzida foi coletada a partir da instalação aleatória de quatro coletores quadrados de $0,25 \mathrm{~m}^{2}(0,5 \mathrm{~m} \times 0,5 \mathrm{~m})$ (Figura 1$)$. Os coletores possuíam fundo de rede de náilon (malha de $1 \mathrm{~mm}$ ) e pés que os mantinham suspensos a $0,20 \mathrm{~m}$ do solo, evitando, assim, contato com a superfície do solo. 
TABELA 1: Caracterização química e composição granulométrica dos solos (profundidade 0-5 cm) sob três diferentes povoamentos florestais no Sudoeste da Bahia.

TABLE 1: Chemical and granulometric composition of soils $(0-5 \mathrm{~cm}$ depth) under three different forest stands in the southwestern Bahia.

\begin{tabular}{|c|c|c|c|c|c|c|c|c|c|c|c|c|}
\hline \multirow{2}{*}{ Cobertura } & $\mathrm{pH}$ & MO & $\mathrm{H}+\mathrm{Al}$ & $\mathrm{P}$ & K & $\mathrm{Ca}$ & $\mathrm{Mg}$ & V & $\mathrm{m}$ & Argila & Areia & Silte \\
\hline & & $\mathrm{g} \mathrm{dm}^{-3}$ & \multicolumn{5}{|c|}{- cmolc $\mathrm{dm}^{3}-$} & \multicolumn{2}{|c|}{$-----\%---$} & \multicolumn{3}{|c|}{$\longrightarrow \mathrm{g} \mathrm{kg}^{-1}-$} \\
\hline Mata de cipó & 4,3 & 46,0 & 10,1 & 2,0 & 0,12 & 1,20 & 0,78 & 16,3 & 43,83 & 450 & 540 & 10 \\
\hline Madeira nova & 5,6 & 16,3 & 2,6 & 1,3 & 0,20 & 1,13 & 1,00 & 46,9 & 13,0 & 380 & 608 & 12 \\
\hline Eucalipto & 4,8 & 26,3 & 5,8 & 2,0 & 0,08 & 0,63 & 0,58 & 18,1 & 41,11 & 490 & 500 & 10 \\
\hline
\end{tabular}

Obs.: análises realizadas de acordo com EMBRAPA (1979).

Em que: $\mathrm{pH}$ (água); $\mathrm{P}$ e K extraíveis por Mehlich-1; $\mathrm{Ca}, \mathrm{Mg}$ e Al trocáveis por $\mathrm{KCl} 1 \mathrm{~mol} \mathrm{~L}^{-1}$ e matéria orgânica (MO) por oxidação com $\mathrm{Na}_{2} \mathrm{Cr}_{2} \mathrm{O}_{7} 4 \mathrm{~N}$. Para cada cobertura florestal foram utilizadas quatro amostras compostas por 20 amostras simples, coletadas das mesmas parcelas utilizadas para coleta de serapilheira.

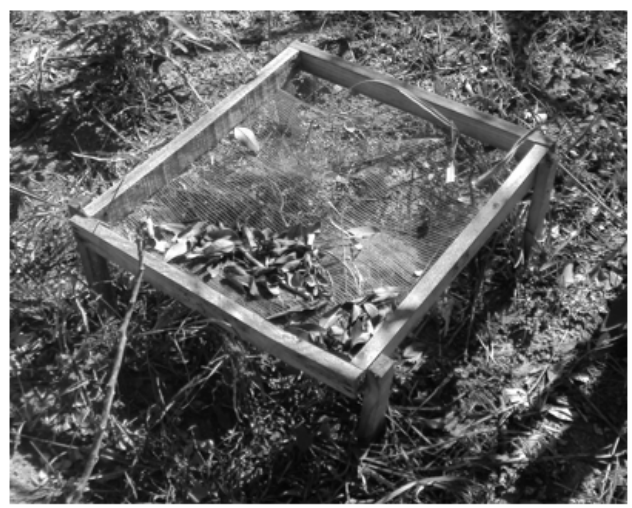

FIGURA 1: Coletor de serapilheira instalado no campo.

FIGURE 1: Litter collectors installed in the field.

\section{Análises da serapilheira produzida}

O tecido vegetal depositado mensalmente dos coletores foi triado separando-se quatro frações (folhas, galhos, casca e estruturas reprodutivas), secos em estufa $\left(\right.$ a $60^{\circ} \mathrm{C}$ por $\left.72 \mathrm{~h}\right)$ e pesados. A partir dos resultados de peso seco das frações foram avaliadas as produções mensais e total (de julho de 2010 a abril de 2011) de cada uma das áreas, conforme fórmulas a seguir:

$$
P S_{m \hat{e ̂ s} / h a}=\frac{\left(P S_{m e \hat{s}} * 10.000\right)}{A_{C}} \quad P S_{\text {total } / h a}=\sum P S_{m e ̂ s} / h a
$$

Em que: $P S_{\text {mês }}=$ Produção de serapilheira obtida em cada mês estudado $\left(\mathrm{kg} \mathrm{mês}^{-1}\right) ; P S_{\text {mês } h a}=$ Produção mensal de serapilheira por hectare $\left(\mathrm{kg} \mathrm{ha}^{-1} \mathrm{mês}^{-1}\right) ; \mathrm{Ac}$ $=$ Área do coletor $\left(\mathrm{m}^{2}\right) ; P S_{\text {total ha }}=$ Produção total de serapilheira $\left(\mathrm{kg} \mathrm{ha}^{-1}\right)$ (MARTINS e RODRIGUES, 1999).

\section{Dados climáticos}

As variáveis climáticas consideradas foram precipitação, velocidade do vento e temperatura média. Os dados correspondentes ao período de estudo do presente trabalho (julho de 2010 a abril de 2011) foram disponibilizados pela Estação Meteorológica da Universidade Estadual do Sudoeste da Bahia (ESMET), conforme Tabela 2.

\section{Análise estatística}

Para comparar a produção mensal de serapilheira (das frações e total) entre os povoamentos, bem como entre as frações, foi utilizado o teste t de Student a 5\% de significância, por meio do programa estatístico SISVAR $\AA$. Além disso, com propósito de avaliar a influência dos fatores climáticos na produção de serapilheira ao longo do período de estudo, foram estabelecidas correlações de Pearson a 5\% de significância entre aporte de serapilheira e variáveis climáticas (precipitação, velocidade do vento e temperatura média), empregando-se o programa $S A E G \AA$ v.9.1.

\section{RESULTADOS E DISCUSSÃO}

\section{Produção e composição da serapilheira}

A produção mensal média de serapilheira encontrada na mata de cipó $\left(544,6 \mathrm{~kg} \mathrm{ha}^{-1}\right.$ mês 1) (Tabela 3) está de acordo com Brown e Lugo (1982) que relataram que em florestas tropicais e subtropicais o aporte médio de serapilheira pode variar de 83,3 a $1.275,0 \mathrm{~kg} \mathrm{ha}^{-1}$ mês $^{-1}$. Costa et al. (2010), estudando a produção de serapilheira em 
TABELA 2: Dados climáticos obtidos pela Estação Meteorológica da Universidade Estadual do Sudoeste da Bahia, Vitória da Conquista - BA, durante o período de estudo (julho de 2010 a abril de 2011).

TABLE 2: Climatic data obtained from the Meteorological Station of the State University of Southwest Bahia, Vitória da Conquista, Bahia state, during the study period from July 2010 to April 2011.

\begin{tabular}{lccc}
\hline \multicolumn{1}{c}{ Mês/Ano } & Ppt $(\mathrm{mm})$ & Vent $\left(\mathrm{km} \mathrm{h}^{-1}\right)$ & Tmed $\left({ }^{\circ} \mathrm{C}\right)$ \\
\hline Julho/2010 & 25,70 & 3,20 & 18,33 \\
Agosto/2010 & 42,40 & 2,97 & 18,50 \\
Setembro/2010 & 12,50 & 3,27 & 20,47 \\
Outubro/2010 & 9,80 & 3,23 & 23,43 \\
Novembro/2010 & 158,30 & 2,37 & 23,27 \\
Dezembro/2010 & 140,60 & 2,20 & 23,28 \\
Janeiro/2011 & 31,50 & 2,50 & 22,63 \\
Fevereiro/2011 & 32,20 & 2,83 & 23,63 \\
Março/2011 & 81,00 & 2,23 & 23,67 \\
Abril/2011 & 67,90 & 2,33 & 21,47 \\
\hline
\end{tabular}

Em que: Ppt: precipitação; Vent: velocidade do vento; Tmed: temperatura média.

fragmentos de caatinga, verificaram uma média de $282,0 \mathrm{~kg} \mathrm{ha}^{-1} \mathrm{mês}^{-1}$, enquanto Pereira et al. (2008), em Mata Atlântica, encontraram $758,3 \mathrm{~kg} \mathrm{ha}^{-1}$ mês 1. A Floresta Estacional Semidecidual Montana de Vitória da Conquista (BA), objeto de estudo deste trabalho, localiza-se em uma zona de transição entre caatinga e Mata Atlântica (SOARES FILHO, 2000), o que pode explicar o valor intermediário encontrado nessa cobertura.

No plantio de madeira nova, a produção média mensal foi de $177,5 \mathrm{~kg}$ ha $^{-1}$ mês $^{-1}$ (Tabela 3). Apesar de ainda não existirem informações disponíveis na literatura acerca do aporte de serapilheira dessa espécie, pode-se verificar que a sua produção é semelhante a valores observados para Luehea grandiflora Mart. (açoita- cavalo), estabelecida em consórcio com outras espécies arbóreas (em média 199,8 $\mathrm{kg} \mathrm{ha}^{-1}$ mês ${ }^{-1}$ ) (DUARTE, 2007), e é inferior ao aporte mensal encontrado para a espécie Mimosa caesalpiniifolia Benth. (sabiá), em plantio puro (espaçamento $3 \mathrm{~m} \mathrm{x}$ $3 \mathrm{~m}$ ) e com seis anos de idade (em média $669,7 \mathrm{~kg}$ ha $^{-1}$ mês $^{-1}$ ) (FERREIRA et al., 2007).

A produção média mensal observada no eucalipto $\left(522,6 \mathrm{~kg} \mathrm{ha}^{-1}\right.$ mês $\left.^{-1}\right)$ é inferior à encontrada por Balieiro et al. (2004) em plantio homogêneo do mesmo gênero (Eucalyptus sp.) em espaçamento $3 \mathrm{~m} \times 3 \mathrm{~m}$ e com sete anos de idade, no município de Seropédica - RJ (986,7 $\mathrm{kg} \mathrm{ha}^{-1}$ mês $\left.{ }^{-1}\right)$, e próximo à produção observada por Melo e Resck (2003) em povoamento de Eucalyptus camaldulensis, com 16 anos de idade, em

TABELA 3: Produção mensal média de serapilheira em um período de dez meses em três povoamentos florestais no Sudoeste da Bahia.

TABLE 3: Average monthly production of litter in a ten-month period in three forest settlements in southwestern Bahia.

\begin{tabular}{lcrrrc}
\hline \multirow{2}{*}{ COBERTURA } & \multicolumn{5}{c}{ Frações da Serapilheira $\left(\mathrm{kg} \mathrm{ha}^{-1}\right.$ mês $\left.^{-1}\right)$} \\
\cline { 2 - 6 } & Folhas & \multicolumn{1}{c}{ Galhos } & Cascas & Est. Reprod. & Total \\
\hline Mata de Cipó & $380,08 \mathrm{Aa}$ & $129,90 \mathrm{Ab}$ & $12,15 \mathrm{Bc}$ & $22,50 \mathrm{Bc}$ & $544,63 \mathrm{~A}$ \\
Madeira Nova & $114,97 \mathrm{Ca}$ & $52,99 \mathrm{Bb}$ & $2,61 \mathrm{Bc}$ & $6,91 \mathrm{Cc}$ & $177,48 \mathrm{~B}$ \\
Eucalipto & $309,46 \mathrm{Ba}$ & $130,99 \mathrm{Ab}$ & $33,93 \mathrm{Ac}$ & $48,20 \mathrm{Ac}$ & $522,58 \mathrm{~A}$ \\
\hline
\end{tabular}

Em que: Est. reprod., materiais reprodutivos; Médias seguidas pela mesma letra maiúscula na coluna e minúscula na linha não diferem entre si pelo teste $t$. 
Planaltina - DF (626,2 $\mathrm{kg} \mathrm{ha}^{-1}$ mês $\left.^{-1}\right)$.

Ao comparar a produção média mensal de serapilheira entre as coberturas estudadas, verificouse que mata de cipó e eucalipto assemelharam-se estatisticamente, apresentando valores superiores ao observado na madeira nova (Tabela 3). Essa variação pode ser atribuída a características de estrutura dos povoamentos, uma vez que a área de madeira nova apresentava árvores com menor porte e dossel mais aberto. De acordo com Vidal et al. (2007), o porte das árvores refletido no tamanho do dossel pode ser mais determinante na produção mensal de serapilheira do que a abundância de espécies. GamaRodrigues e Barros (2002), estudando a produção de serapilheira em diferentes ecossistemas florestais no Sudeste da Bahia, observaram semelhança estatística entre os aportes de serapilheira de uma floresta nativa (Floresta Ombrófila Densa) e de povoamentos de Eucalyptus grandis Hill, que foram significativamente inferiores ao aporte de plantios de Joannesia princeps Vell., espécie nativa da região dos tabuleiros.

Considerando-se a produção mensal de cada uma das frações, verificou-se que o aporte de galhos foi significativamente menor na madeira nova e não variou entre mata de cipó e eucalipto. Por sua vez, as frações folhas e estruturas reprodutivas apresentaram variação significativa entre todas as coberturas estudadas (Tabela 3). A produção mensal média de folhas foi superior na mata nativa, seguida por eucalipto e madeira nova, enquanto a produção de materiais reprodutivos variou na ordem: eucalipto $>$ mata de cipó > madeira nova. Gama-Rodrigues e Barros (2002) também verificaram maior aporte de folhas em mata nativa e de estruturas reprodutivas em plantios do gênero Eucalyptus. Dada a grande variabilidade fenológica, diferenças na produção das frações da serapilheira entre espécies são comuns e já foram relatadas em vários trabalhos com florestas naturais e plantadas (SANKARAN, 1993; MARTINS e RODRIGUES, 1999; PAGANO e DURIGAN, 2001; FERREIRA et al., 2007).

A produção mensal da fração casca foi superior no eucalipto e não variou entre mata de cipó e madeira nova, o que pode indicar uma similaridade entre espécies nativas quanto à produção de casca (Tabela 3). Devido a sua pequena participação na produção total de serapilheira, verifica-se que em alguns estudos as cascas não são quantificadas (SILVA et al., 2007; PINTO et al., 2008; PAULA et al., 2009).

As produções acumuladas de serapilheira foram de 5.446, 5.226 e $1.795 \mathrm{~kg} \mathrm{ha}^{-1}$ nas áreas de mata de cipó, eucalipto e madeira nova, respectivamente (Tabela 4). Os maiores aportes foram verificados nos meses de julho e agosto, nas áreas de mata de cipó e eucalipto, e nos meses de julho e setembro, no povoamento de madeira nova. Maman et al. (2007), estudando produção e acúmulo de serapilheira, ao longo de 10 meses, em ecossistemas florestais do Estado do Mato Grosso, encontraram produção total de $2.220 \mathrm{~kg} \mathrm{ha}^{-1}$, em mata de galeria, e de $2.980 \mathrm{~kg} \mathrm{ha}^{-1}$, em cerradão.

As folhas representaram maior proporção da serapilheira produzida nas três coberturas, com diferenças significativas em relação às demais frações (Tabela 3), contribuindo, em média, com 65\% da produção total (Tabela 4). Diversos estudos em florestas naturais e plantadas também constataram que a folha constitui o principal componente do material aportado sobre o solo (ANDRADE et al., 2008; BARNES et al., 1998; MARTINS e RODRIGUES, 1999; SCHUMACHER et al., 2004). Após a fração foliar, em todas as coberturas estudadas, a participação média das outras frações ocorreu na ordem: galhos $(26,19 \%)>$ materiais reprodutivos $(5,73 \%) \geq$ cascas $(3,38 \%)$ (Tabela 4$)$. Este mesmo padrão de distribuição foi verificado em plantações mistas de $M$. caesalpiniifolia e Acacia auriculiformis A. Cunn. ex Benth. no Estado do Rio de Janeiro (COSTA et al., 2004) e em florestas naturais como cerradão (SILVA et al., 2007), caatinga (ANDRADE et al., 2008) e Mata Atlântica (PINTO et al., 2008).

\section{Produção de serapilheira e variáveis climáticas}

$\mathrm{Na}$ Tabela 5 são apresentados os coeficientes de correlação entre a produção mensal de serapilheira (total e das frações) e variáveis meteorológicas. Em todas as coberturas estudadas, foram verificadas correlações negativas significativas da temperatura média do ar com a produção total e com a produção de folhas (Tabela 5). Os maiores aportes ocorreram entre os meses de julho e setembro (Tabela 4), período com menores temperaturas e precipitação reduzida (Tabela 2). Segundo Chabot e Hicks (1982), a abscisão das folhas pode ocorrer pela ação de baixas temperaturas e deficit hídrico. Isto tanto por modificar a atividade celular, promovendo a senescência, quanto por indução hormonal gerenciada pelo genoma da planta. Andrade et al. (2000), em plantio homogêneo de 
TABELA 4: Produção mensal e contribuição das diferentes frações formadoras da serapilheira em um período de dez meses em três povoamentos florestais no Sudoeste da Bahia.

TABLE 4: Monthly production and contribution of the different fractions forming the litter in a tenmonth period in three forest settlements in southwestern Bahia.

\begin{tabular}{|c|c|c|c|c|c|c|c|c|c|}
\hline \multirow{4}{*}{ Mês/Ano } & \multicolumn{9}{|c|}{ Frações da Serapilhiera } \\
\hline & \multicolumn{2}{|c|}{ Folhas } & \multicolumn{2}{|c|}{ Galhos } & \multicolumn{2}{|c|}{ Cascas } & \multicolumn{2}{|c|}{ Est. Reprod. } & \multirow{2}{*}{$\frac{\text { Total }}{\mathrm{kg} \mathrm{ha}^{-1}}$} \\
\hline & $\mathrm{kg} \mathrm{ha}^{-1}$ & $\%$ & $\mathrm{~kg} \mathrm{ha}^{-1}$ & $\%$ & $\mathrm{~kg} \mathrm{ha}^{-1}$ & $\%$ & $\mathrm{~kg} \mathrm{ha}^{-1}$ & $\%$ & \\
\hline & \multicolumn{9}{|c|}{ Mata de Cipó } \\
\hline Julho/2010 & 547,23 & 72,91 & 192,80 & 25,69 & 2,03 & 0,27 & 8,50 & 1,13 & 750,56 \\
\hline Agosto/2010 & 634,73 & 73,70 & 222,30 & 25,81 & 1,48 & 0,17 & 2,77 & 0,32 & 861,28 \\
\hline Setembro/2010 & 455,23 & 82,82 & 79,35 & 14,44 & 7,50 & 1,36 & 7,58 & 1,38 & 549,66 \\
\hline Outubro/2010 & 345,45 & 65,00 & 161,43 & 30,38 & 4,48 & 0,84 & 20,08 & 3,78 & 531,44 \\
\hline Novembro/2010 & 282,10 & 70,81 & 84,13 & 21,12 & 13,28 & 3,33 & 18,86 & 4,73 & 398,37 \\
\hline Dezembro/2010 & 350,28 & 77,02 & 63,05 & 13,86 & 19,99 & 4,40 & 21,475 & 4,72 & 454,795 \\
\hline Janeiro/2011 & 307,15 & 72,84 & 94,10 & 22,32 & 6,20 & 1,47 & 14,20 & 3,37 & 421,65 \\
\hline Fevereiro/2011 & 200,28 & 59,30 & 80,45 & 23,82 & 31,25 & 9,25 & 25,78 & 7,63 & 337,76 \\
\hline Março/2011 & 319,80 & 60,44 & 166,00 & 31,38 & 12,25 & 2,32 & 31,03 & 5,86 & 529,08 \\
\hline Abril/2011 & 358,53 & 58,61 & 155,35 & 25,40 & 23,08 & 3,77 & 74,77 & 12,22 & 611,73 \\
\hline \multirow[t]{2}{*}{ Total } & 3800,78 & 69,79 & 1298,96 & 23,85 & 121,54 & 2,23 & 225,045 & 4,13 & 5446,33 \\
\hline & \multicolumn{9}{|c|}{ Madeira Nova } \\
\hline Julho/2010 & 168,53 & 70,95 & 65,63 & 27,63 & 1,25 & 0,53 & 2,13 & 0,90 & 237,54 \\
\hline Agosto/2010 & 145,55 & 72,16 & 54,65 & 27,09 & 0,00 & 0,00 & 1,50 & 0,74 & 201,7 \\
\hline Setembro/2010 & 138,58 & 64,43 & 62,23 & 28,93 & 4,08 & 1,90 & 10,18 & 4,73 & 215,07 \\
\hline Outubro/2010 & 104,03 & 60,12 & 65,63 & 37,93 & 1,25 & 0,72 & 2,13 & 1,23 & 173,04 \\
\hline Novembro/2010 & 102,70 & 76,81 & 23,38 & 17,49 & 3,90 & 2,92 & 3,73 & 2,79 & 133,71 \\
\hline Dezembro/2010 & 92,63 & 66,04 & 41,88 & 29,86 & 0,00 & 0,00 & 5,75 & 4,10 & 140,26 \\
\hline Janeiro/2011 & 106,13 & 62,77 & 42,80 & 25,31 & 6,45 & 3,81 & 13,70 & 8,10 & 169,08 \\
\hline Fevereiro/2011 & 90,23 & 58,72 & 56,95 & 37,06 & 0,00 & 0,00 & 6,48 & 4,22 & 153,66 \\
\hline Março/2011 & 86,78 & 65,24 & 35,53 & 26,71 & 3,73 & 2,80 & 6,98 & 5,25 & 133,02 \\
\hline Abril/2011 & 114,65 & 54,85 & 74,78 & 35,78 & 4,43 & 2,12 & 15,15 & 7,25 & 209,01 \\
\hline \multirow[t]{2}{*}{ Total } & 1149,81 & 65,10 & 523,46 & 29,64 & 25,09 & 1,42 & 67,73 & 3,84 & 1766,09 \\
\hline & \multicolumn{9}{|c|}{ Eucalipto } \\
\hline Julho/2010 & 378,88 & 58,25 & 213,38 & 32,80 & 22,13 & 3,40 & 36,10 & 5,55 & 650,49 \\
\hline Agosto/2010 & 450,40 & 67,76 & 127,83 & 19,23 & 36,48 & 5,49 & 49,98 & 7,52 & 664,69 \\
\hline Setembro/2010 & 309,35 & 58,09 & 133,40 & 25,05 & 26,30 & 4,94 & 63,48 & 11,92 & 532,53 \\
\hline Outubro/2010 & 315,48 & 62,13 & 119,20 & 23,48 & 42,58 & 8,39 & 30,50 & 6,01 & 507,76 \\
\hline Novembro/2010 & 228,33 & 53,86 & 108,38 & 25,56 & 40,85 & 9,64 & 46,40 & 10,94 & 423,96 \\
\hline Dezembro/2010 & 218,28 & 58,63 & 93,56 & 25,13 & 23,40 & 6,29 & 37,05 & 9,95 & 372,29 \\
\hline Janeiro/2011 & 212,10 & 55,05 & 108,00 & 28,03 & 26,83 & 6,96 & 38,38 & 9,96 & 385,31 \\
\hline Fevereiro/2011 & 326,63 & 61,05 & 119,08 & 22,26 & 34,15 & 6,38 & 55,18 & 10,31 & 535,04 \\
\hline Março/2011 & 292,53 & 51,82 & 175,20 & 31,03 & 33,35 & 5,91 & 63,48 & 11,24 & 564,56 \\
\hline Abril/2011 & 362,73 & 61,54 & 112,00 & 19,00 & 53,20 & 9,03 & 61,48 & 10,43 & 589,41 \\
\hline Total & 3094,71 & 59,22 & 1310,03 & 25,07 & 339,27 & 6,49 & 482,03 & 9,22 & 5226,04 \\
\hline
\end{tabular}

Em que: Est. reprod., estruturas reprodutivas 
M. caesalpiniifolia, e König et al. (2002), em Floresta Estacional Decidual, também verificaram maiores aportes de serapilheira nos meses de menor temperatura e precipitação. Dias et al. (2002) mencionam que a maior produção de serapilheira em períodos mais frios e secos do ano constitui uma característica típica de florestas tropicais estacionais.

No plantio de madeira nova, além da associação significativa com a temperatura, a produção de serapilheira correlacionou-se significativamente com as variáveis precipitação e velocidade do vento (Tabela 5), com maiores deposições ocorrendo nos períodos mais frios, secos e com ventos mais intensos. Esse resultado pode ser atribuído a maior exposição do plantio, uma vez que o dossel mais aberto permite grande incidência de radiação solar e maior efeito do vento, contribuindo para o aumento da temperatura e diminuição da umidade. Resultados observados por Cianciaruso et al. (2005), em área de Cerradão no Estado de São Paulo, demonstraram antagonismo da curva de produção de serapilheira em relação às curvas de umidade relativa e temperatura média do ar.

No eucalipto, a fração galhos apresentou um padrão de variação temporal bastante semelhante ao longo dos meses de estudo. Já na mata de cipó e madeira nova a distribuição foi desuniforme, mas com picos nos meses de março e outubro, respectivamente, que podem ser atribuídos à interferência de variáveis climáticas, uma vez que foram verificadas associações significativas desta fração com o vento e precipitação, na madeira nova, e com a temperatura, na mata de cipó (Tabela 5). A participação desta fração na serapilheira produzida costuma ser bastante variada (CESAR, 1993; COSTA et al., 2004; PINTO et al., 2008) e ocorre normalmente em resposta a eventos bióticos e abióticos anteriores a sua deposição, sendo marcada pela heterogeneidade temporal com baixa correlação com as variáveis climáticas (KÖNIG et al., 2002; PINTO et al., 2008).

Em geral, a fração casca não apresentou um padrão sazonal de distribuição. Apenas na mata de cipó verificou-se correlação significativa positiva da temperatura com esta fração (Tabela 5), sugerindo maiores deposições em períodos mais quentes. $\mathrm{Na}$ madeira nova, o aporte de casca mostrou-se bastante irregular durante o ano, enquanto no eucalipto verificou-se pouca variação da produção entre os meses de estudo.

Na mata de cipó houve menor deposição de estruturas reprodutivas durante os meses de julho e agosto, ocasião com menores temperaturas médias, contrariando indicações de que épocas com maiores precipitações e temperaturas representam os principais períodos da sua produção (PINTO et al., 2008). Na madeira nova, a produção de estruturas

TABELA 5: Coeficiente de correlação de Pearson entre a variação mensal da produção de serapilheira (total e das frações) e variáveis meteorológicas.

TABLE 5: Pearson's correlation coefficient between the monthly variation of litter production (total and fractions) and the meteorological variables.

\begin{tabular}{cccccc}
\hline \multirow{2}{*}{ Variável climática } & \multicolumn{5}{c}{ Serapilheira } \\
\cline { 2 - 6 } & Total & Folhas & Galhos & Casca & Est. Reprod. \\
\hline Precipitação & & \multicolumn{3}{c}{ Mata de cipó } \\
Vento & $-0,32$ & $-0,30$ & $-0,36$ & 0,35 & $-0,52$ \\
Temperatura & 0,41 & 0,50 & 0,31 & $-0,50$ & 0,32 \\
\hline Precipitação & $-0,88^{*}$ & $-0,93^{*}$ & $-0,60^{*}$ & $0,56^{*}$ & $-0,08$ \\
Vento & & & Madeira nova & $-0,39$ \\
Temperatura & $-0,70^{*}$ & $-0,44$ & $-0,71^{*}$ & 0,01 & 0,20 \\
\hline Precipitação & $0,70^{*}$ & $0,66^{*}$ & $0,59 *$ & $-0,30$ & 0,17 \\
Vento & $-0,81^{*}$ & $-0,97^{*}$ & $-0,47$ & & $-0,00$ \\
Temperatura & $-0,49$ & $-0,51$ & Eucalipto & 0,10 & $-0,19$
\end{tabular}

Em que: *correlações significativas a 5\% de probabilidade de erro; Est. Reprod. = estruturas reprodutivas. 
reprodutivas ocorreu em maior quantidade durante o mês de janeiro, período de floração da espécie, enquanto no eucalipto, a distribuição ao longo dos meses mostrou-se mais uniforme, provavelmente pelo fato de que os frutos de eucalipto permanecem aderidos à árvore por longos períodos.

Os resultados sugeriram que a variação do aporte de serapilheira esteve relacionada à estrutura da floresta. Assim, estudos futuros podem ser realizados buscando uma metodologia que permita relacionar o tamanho do dossel e porte das árvores com a produção de serapilheira dos povoamentos estudados.

\section{CONCLUSÕES}

A produção mensal de serapilheira no povoamento de madeira nova foi três vezes menor $\left(177,5 \mathrm{~kg} \mathrm{ha}^{-1}\right.$ mês $\left.^{-1}\right)$ que na mata de cipó e povoamento de eucalipto (média de 533,6 $\mathrm{kg} \mathrm{ha}^{-1}$ mês $\left.{ }^{-1}\right)$.

A variação temporal do aporte de serapilheira na madeira nova mostra-se mais sensível às variações do clima do que na mata de cipó e povoamento de eucalipto.

A contribuição das frações da serapilheira obedeceu a uma mesma ordem em todas as coberturas estudadas: folhas $>$ galhos $>$ estruturas reprodutivas $>$ cascas.

\section{REFERÊNCIAS BIBLIOGRÁFICAS}

ANDRADE, A. G. et al. Deposição e decomposição da serapilheira em povoamentos de Mimosa caesalpiniifolia, Acacia mangium e Acacia holosericea com quatro anos de idade em planossolo. Revista Brasileira de Ciência do Solo, v. 24, n. 4, p. 777-785, 2000.

ANDRADE R. L. et al. Deposição de Serrapilheira em Área de Caatinga na RPPN Fazenda Tamanduá, Santa Terezinha - PB. Revista Caatinga, v. 21, n. 2. p. 223-230, 2008.

ALVES, R. A. et al. Aporte e decomposição de serrapilheira em área de caatinga, na Paraíba. Revista Biologia e Ciência da Terra, v. 6, n. 2, p. 194-203, 2006.

ARATO, H. D. et al.. Produção e decomposição de serapilheira em um sistema agroflorestal implantado para recuperação de área degradada em Viçosa-MG. Revista Árvore, Viçosa, v. 27, n. 5, p. 715-721, 2003.

ASSOCIAÇÃO BRASILEIRA DE PRODUTORES
DE FLORESTAS PLANTADAS (ABRAF). Anuário estatístico da ABRAF 2010 - ano base 2009. Brasília, DF, 2010. 140 p.

BALIEIRO, F. C. et al. Dinâmica da serapilheira e transferência de nitrogênio ao solo, em plantios de Pseudosamanea guachapele e Eucalyptus grandis. Pesq. Agropec. Bras., Brasília, v. 39, n. 6, p. $597-$ 601, 2004.

BARNES, B. V. et al. Forest Ecology. New York: John Wiley, $1998.774 \mathrm{p}$.

BRASIL. Conselho Nacional do Meio Ambiente CONAMA. Resolução $\mathbf{n}^{\mathbf{0}}$. 1, de 31 de Janeiro de 1994. Diário Oficial da União, de 03 de Fevereiro de 1994, Seção1, páginas 1684-1685.

BROWN, S.; LUGO, A. E. The storage and production of organic matter in tropical forest and their role in global carbon cycle. Biotropica, v. 14, n. 3, p. 161-187, 1982.

CARVALHO, P. E. R. Espécies florestais brasileiras: recomendações silviculturais, potencialidades e uso da madeira. Colombo: EMBRAPA/CNPF, 1994. $640 \mathrm{p}$.

CESAR, O. Produção de serapilheira na mata mesófila semidecídua da Fazenda Barreiro Rico, Município de Anhembi, SP. Revista Brasileira de Biologia. v. 53 p. 671-681, 1993.

CHABOT, B. F.; HICKS, D. J. The ecology of leaf life span. Annual Rewiew of Ecology and Systematics v. 13, p. 229-243, 1982.

CIANCIARUSO, M. V. et al. Produção de serrapilheira e decomposição do material foliar em um cerradão na Estação Ecológica de Jataí, município de Luiz Antônio, SP, Brasil. Acta Botânica Brasileira. p. 49-59, 2005.

COSTA, G. S. et al. Aporte de nutrientes pela serapilheira em uma área degradada e revegetada com leguminosas arbóreas. Revista Brasileira de Ciência do Solo. v. 28, p. 919-927, 2004.

COSTA, C. C. A. et al. Análise comparativa da produção de serapilheira em fragmentos arbóreos e arbustivos em área de Caatinga na Flona de AçuRN. Revista Árvore, Viçosa, v. 34, n. 2, p. 259-265, 2010.

DIAS, H. C. T. et al. Variação temporal de nutrientes na serapilheira de um fragmento de floresta estacional semidecidual em Lavras, Minas Gerais Brasil. Cerne, Lavras, v. 8, n. 2, p. 1-16, 2002.

DUARTE, E. M. G. Ciclagem de nutrientes por árvores em Sistemas Agroflorestais na Mata Atlântica. 2007. 132 f. Dissertação (Mestrado em Solos e Nutrição de Plantas). Universidade Federal 
de Viçosa, Viçosa, 2007.

EMPRESA BRASILEIRA DE PESQUISA AGROPECUÁRIA (EMBRAPA). Centro Nacional de Pesquisa de Solos (Rio de Janeiro). Sistema Brasileiro de Classificação de solos. 2. ed. Rio de Janeiro, 2006. 306 p.

EMPRESA BRASILEIRA DE PESQUISA AGROPECUÁRIA(EMBRAPA). Serviço Nacional de Levantamento e Classificação de Solos. Manual de métodos de análise de solo. Rio de Janeiro: Embrapa-SNLCS, 1979. 255 p.

FACELLI, J. M.; PICKETT, S. T. A. Plant litter: its dynamics and effects on plant community struture. The Botanical Review, v. 57, p. 1-32, 1991.

FERREIRA, R. L. C. et al. Deposição e acúmulo de matéria seca e nutrientes em serapilheira em um bosque de sabiá. Revista Árvore, Viçosa, v. 31, n. 1, p. 7-12, 2007.

GAMA-RODRIGUES, A. C.; BARROS, N. F. Ciclagem de nutrientes em floresta natural e em plantios de eucalipto e de dandá no sudeste da Bahia, Brasil. Revista Árvore, Viçosa, v. 26, n. 2, p. 193-207, 2002.

KÖNIG, F. G. et al. Avaliação da sazonalidade da produção de serapilheira numa Floresta Estacional Decidual no município de Santa Maria-RS. Revista Árvore. v. 26, p. 26-435, 2002.

LORENZI, H. Árvores brasileiras: manual de cultivo de plantas arbóreas nativas do Brasil. Nova Odessa: Plantarum, 2002. v. 1.

MACHADO, F. A. et al. Produção e qualidade da serrapilheira de três leguminosas arbóreas nativas do nordeste do Brasil. Arch. Zootec. v. 61, n. 235, 2012.

MAMAN, A. P. et al. Produção e acúmulo de serapilheira e decomposição foliar em mata de galeria e cerradão no sudoeste de Mato Grosso. Revista de Ciências Agro-Ambientais. v. 5, n. 1, p. 71- 84, 2007.

MARTINS, S. V.; RODRIGUES, R. R. Produção de serapilheira em clareiras de uma floresta estacional de uma floresta estacional semidecidual no município de Campinas, SP. Revista Brasileira de Botânica, v. 68, p. 257-278, 1999.

MELO, J. T.; RESCK, D. V. S. Retorno ao Solo de Nutrientes de Serrapilheira de Eucalyptus camaldulensis no Cerrado do Distrito Federal. Planantina: Embrapa Cerrados, 2003. 17 p. (Boletim de Pesquisa e Desenvolvimento/Embrapa Cerrados, 109).

PAGANO, S. N.; DURIGAN, G. Aspectos da Ciclagem dos Nutrientes em Matas Ciliares do Oeste do estado de São Paulo, Brasil. In: RODRIGUES, R.R.; LEITÃO FREITAS, H.F. (eds). Matas ciliares: conservação e recuperação. 2. ed. São Paulo: FAPESP, 2001. p. 109-131.

PAUlA, J. L.; ALVES, J. L. H. Madeiras nativas: anatomia, dendrologia, produção e uso. Brasília: Fundação Mokiti Okada-MOA. 1997, 543 p.

PAULA, R. R; PEREIRA, M. G.; MENEZES, L. F. T. Aporte de nutrientes e decomposição da serapilheira em três fragmentos florestais periodicamente inundados na ilha da Marambaia, RJ. Ciência Florestal, Santa Maria, v. 19, n. 2, p. 139-148, 2009.

PEREIRA, M. G.; MENEZES, L. F. T.; SCHULTZ, N. Aporte e deposição da serrapilheira na floresta atlântica, Ilha da Marabaia, Mangaratiba, RJ. Ciência Florestal, Santa Maria, v. 18, n. 4, p. 443-454, 2008.

PINTO, S. I. C. et al. Produção de serapilheira em dois estádios sucessionais de floresta estacional semidecidual na reserva Mata do Paraíso, em Viçosa, MG. Revista Árvore, Viçosa, v. 32, n. 3, p. 535-546, 2008.

SANKARAN, K. V. Decomposition of leaf litter of albizia (Paraserianthes falcataria), eucalypt (Eucalyptus tereticornis) and teak (Tectona grandis) in Kerala, India. Forest Ecology and Management, v. 56, n. 1-4, p.225-242, 1993.

SCHUMACHER, M. V. et al. Produção de serapilheira em uma floresta de Araucaria angustifolia (Bertol.) Kuntze no município de Pinhal Grande-RS. Revista Árvore, Viçosa, v. 28, n. 1, p. 29-37, 2004.

SERVIÇO FLORESTAL BRASILEIRO (SFB). Florestas do Brasil em resumo - 2010: dados de 2005 a 2010. Brasília, 2010. 152 p.

SILVA, C. J. et al. Produção de serrapilheira no Cerrado e na floresta de transição Amazônia-Cerrado do Centro Oeste brasileiro. Acta Amazonica, v. 37, n. 4, p. 543-548, 2007.

SOARES FILHO, A. O. Estudo Fitossociológico de duas Florestas em Região Ecotonal no Planalto de Vitória da Conquista, Bahia, Brasil. 2000. 147 f. Dissertação (Mestrado em Ciências). Universidade de São Paulo, São Paulo, 2000.

VELOSO, H. P. et al. Classificação da vegetação brasileira adaptada a um sistema universal. Rio de Janeiro: IBGE, Departamento de Recursos Naturais e Estudos Ambientais, 
1991. $124 \mathrm{p}$.

VIDAL, M. M. et al. Produção de serapilheira em floresta Atlântica secundária numa paisagem fragmentada (Ibiúna, SP): importância da borda e tamanho dos fragmentos Revista Brasileira de
Botânica, v. 30, n. 3, p. 521-532, 2007.

VITOUSEK, P. M.; SANFORD, R. L. Nutrient cycling in moist tropical forest. Annual Review of Ecology and Systematics, v. 17, n. 4, p. 137-167, 1986. 